\title{
Effect of metalloids on crystallization and magnetic behaviour of FeCoSiB based metallic glass
}

\author{
ANSU J KAILATH*, ARVIND KUMAR and AMITAVA MITRA \\ Materials Science and Technology Division, National Metallurgical Laboratory, Jamshedpur 831 007, India
}

MS received 27 October 2005; revised 27 January 2006

\begin{abstract}
A series of amorphous iron-cobalt alloys with varying metalloid, boron and silicon contents were studied for their thermal stability and magnetic behaviour. The crystallization temperature and thermal stability increased with the silicon content. Good soft magnetic properties were observed for the materials with nominal composition, $\left(\mathrm{Fe}_{0.79} \mathrm{Co}_{0.21}\right)_{77} \mathrm{Si}_{12.2} \mathrm{~B}_{10.8}$. The magnetic properties were further improved by annealing.
\end{abstract}

Keywords. Magnetic behaviour; metalloids; crystallization; metallic glass.

\section{Introduction}

Amorphous metals or metallic glasses are novel and promising materials with unique physical, electrical and magnetic properties. Fe-base amorphous alloys have good soft magnetic properties, high strength and good corrosion resistance and have fascinated many researchers. These materials, containing $\sim 80 \%$ ferromagnetic metals and $20 \%$ metalloids like $\mathrm{C}, \mathrm{Si}, \mathrm{B}$ and $\mathrm{P}$, have been extensively used as core materials in power transformers and due to their increased efficiency, an annual savings to the tune of a few billion dollars are estimated. By choosing the composition suitably and through proper heat treatments, the properties of these materials may be tailored to suit one's needs (Masumoto and Egami 1981). Amorphous materials can be prepared by various methods such as vapour deposition, gas atomization, mechanical alloying, splat quenching, sputtering, melt spinning etc. Among these techniques, melt-spinning technique has been widely used for getting continuous ribbons of amorphous soft magnetic materials (Libermann 1983). A cooling rate of $10^{6} \mathrm{~K} / \mathrm{s}$ can be achieved in this technique (Kavesh 1976).

Being metastable in structure, thermal stabilities of these alloys have a decisive role in determining their suitability in different applications for extended period of service. Studies on thermal stabilities provide information regarding the transformation from amorphous to crystalline phases. The physical and chemical properties, which make these alloys suitable for various applications, get changed

\footnotetext{
*Author for correspondence (ansu@ nmlindia.org)
}

as a result of these transformations. Therefore, understanding the crystallization mechanisms is not only of fundamental importance but of technical importance too.

The effect of metalloids on the crystallization and magnetic behaviour of $\mathrm{FeCoSiB}$ metallic ribbons have been studied and the results are discussed in this paper.

\section{Experimental}

Metallic glass ribbons with nominal composition, $\left(\mathrm{Fe}_{0.79}\right.$ $\left.\mathrm{Co}_{0 \cdot 21}\right)_{75+x} \mathrm{Si}_{15-1 \cdot 4 x} \mathrm{~B}_{10+0 \cdot 4 x}(x=0,2,4,6$ and 10$)$, prepared by melt spinning technique with optimized process parameters (Panda et al 2001) were used for the present study. Typical dimensions of the ribbons were $1 \mathrm{~mm}$ in width and $25 \mu \mathrm{m}$ in thickness. The nominal compositions of the alloys are: $\left(\mathrm{Fe}_{0.79} \mathrm{Co}_{0.21}\right)_{75} \mathrm{Si}_{15} \mathrm{~B}_{10} ;\left(\mathrm{Fe}_{0.79} \mathrm{Co}_{0.21}\right)_{77}$ $\mathrm{Si}_{12.2} \mathrm{~B}_{10.8} ; \quad\left(\mathrm{Fe}_{0.79} \mathrm{Co}_{0.21}\right)_{79} \mathrm{Si}_{9.4} \mathrm{~B}_{11.6} ; \quad\left(\mathrm{Fe}_{0.79} \mathrm{Co}_{0.21}\right)_{81} \mathrm{Si}_{6.6} \mathrm{~B}_{12.4}$ and $\left(\mathrm{Fe}_{0.79} \mathrm{Co}_{0.21}\right)_{85} \mathrm{Si}_{1} \mathrm{~B}_{14}$.

Differential scanning calorimetric (DSC) studies were conducted using TA instruments (SDT-Q600)/Perkin Elmer (DSC-7) under argon flow. Both temperature and enthalpy calibrations were done using indium and zinc standards. DSC scans were carried out at different heating rates viz. 10, 20, 30 and $40 \mathrm{~K} / \mathrm{min}$. X-ray diffraction studies were done to characterize the as-received alloys. Annealed ribbons, at temperatures corresponding to transformations observed in the DSC, were also characterized by XRD to identify the crystalline phases formed. X-ray diffraction spectra were recorded with $\mathrm{Co}-\mathrm{K}_{\alpha}$ radiation on a Siefert diffractometer (PTS 3003). The working conditions were $40 \mathrm{kV}$ and $40 \mathrm{~mA}$. Magnetic measurements were done in a computer controlled hysteresis loop tracer developed at the laboratory. 


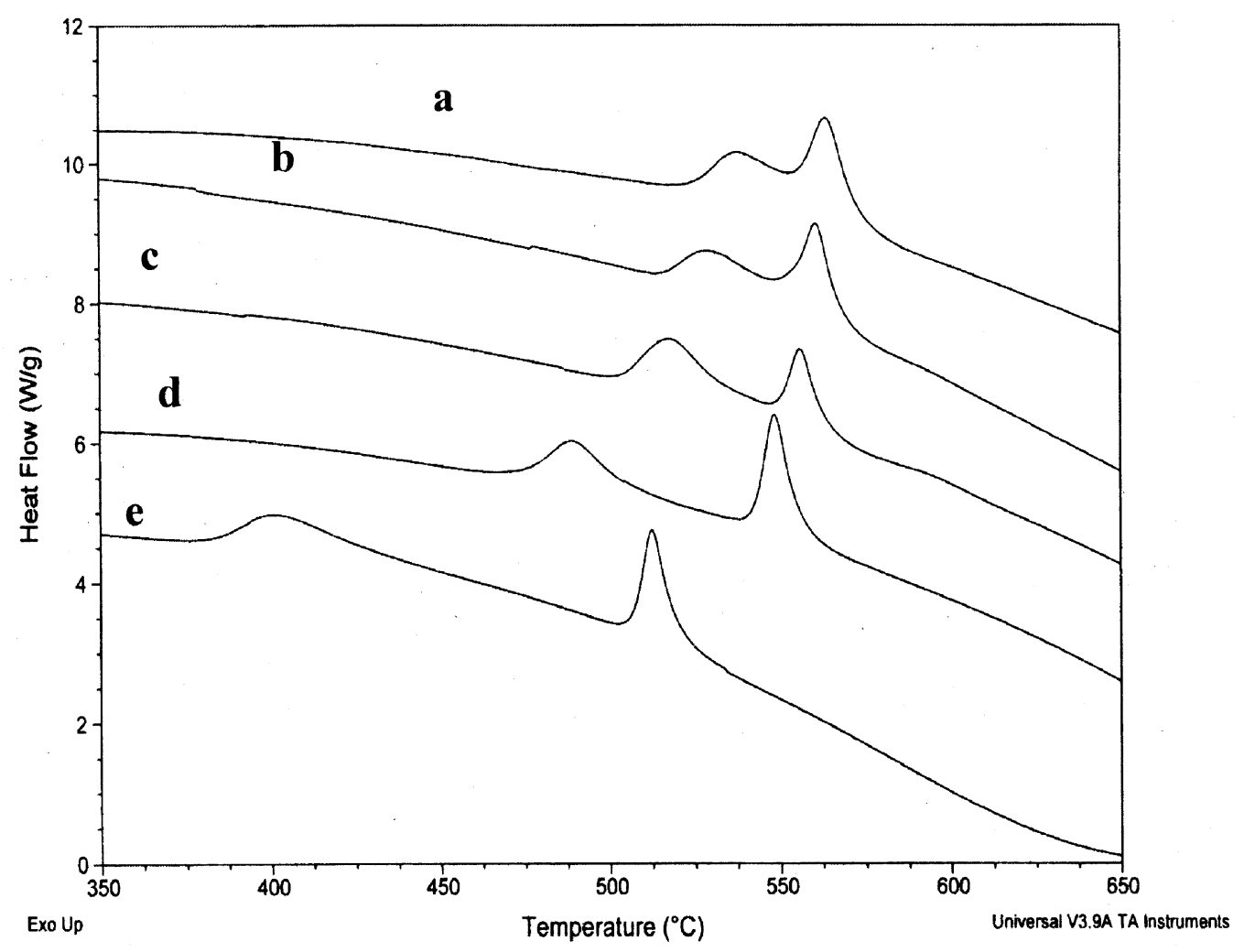

Figure 1. DSC plots of the melt spun ribbons with different $\mathrm{Si}$ contents: $\mathrm{a} . \mathrm{Si}=15 \%$, b. $\mathrm{Si}=12 \cdot 2 \%, \mathrm{c} . \mathrm{Si}=9 \cdot 4 \%$, d. $\mathrm{Si}=6 \cdot 6 \%$ and e. $\mathrm{Si}=1 \%$ recorded at $10 \mathrm{~K} / \mathrm{min}$.

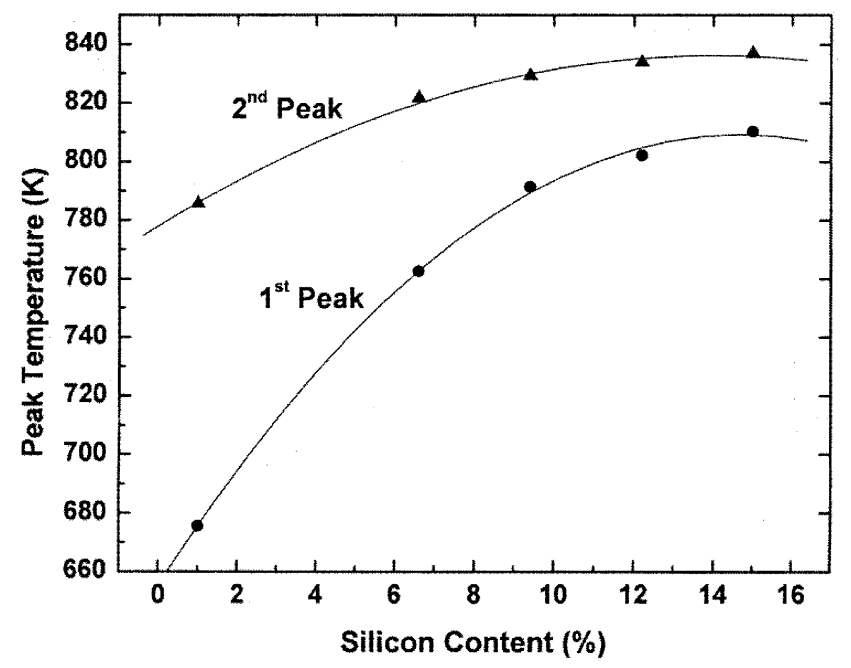

Figure 2. The variation of the first and second crystallization peak temperatures with the silicon content.

\section{Results and discussion}

\subsection{Crystallization studies}

Dynamic DSC scans of as quenched metallic ribbons were done at different heating rates. The DSC pattern of these samples at a heating rate of $10 \mathrm{~K} / \mathrm{min}$ is given in figure 1. Amorphous to crystalline transformation of these alloys consisted of atleast two steps as observed by the two-temperature resolved exotherms in the DSC pattern. These crystallization peaks were found to be partially overlapping for alloys having silicon content above $12 \%$. These two peaks were found to separate further for lower silicon content. It is observed that the difference between the two-peak temperature is $\sim 25^{\circ}$ for the alloy having $15 \%$ silicon and it increased to $\sim 115^{\circ}$ when the silicon content reduced to $1 \%$. In other words, the temperature interval between the two crystallization stages increased with decreasing silicon percentage and hence the partial overlapping of the two exotherms in the DSC scans of higher silicon content resolves into two distinct exotherms as the silicon content decreases. The variation of the peak temperature of the first and second crystallization with silicon content, mentioned above, is plotted in figure 2 . The shift of crystallization onsets to lower temperatures for alloys with lower silicon content indicated the monotonous decrease of the thermal stabilities of the amorphous alloys against crystallization. The crystallization kinetics of the melt spun ribbons were analysed using modified Kissinger equation (Mittemeijer et al 1988; Mitra et al 2003) relating to peak temperature, $T_{\mathrm{p}}$ and scan rate $(S)$ 


$$
\ln \left(T_{\mathrm{p}}^{2} / S\right)=E / R T_{\mathrm{p}}+\ln \left(E / R k_{0}\right)
$$

where $E$ is the activation energy associated with the peak, $R$ the gas constant, $k_{0}$ the pre-exponential factor in the Arrhenius equation for rate constant, $k$,

$$
k=k_{0} \exp (-E / R T),
$$

therefore, the time constant

$$
\tau=\tau_{0} \exp (E / R T) .
$$

Simple expressions for the rate constant, $k_{\mathrm{p}}$ (or time constant), at temperature, $T_{\mathrm{p}}$, obtained by combining (1)-(3) are as follows

$$
\begin{gathered}
k_{\mathrm{p}}=(E / R) \times\left(S / T_{\mathrm{p}}{ }^{2}\right), \\
\tau_{\mathrm{p}}=(R / E) \times\left(T_{\mathrm{p}}{ }^{2} / S\right) .
\end{gathered}
$$

The activation energies of two crystallization stages were determined by measuring the crystallization peak temperature, $T_{\mathrm{p}}$, at different heating rates, $S$, by varying from $10-40 \mathrm{~K} / \mathrm{min}$. The Kissinger plots obtained for the two crystallization processes of different ribbons studied are shown in figures 3 and 4 . It is observed that the Kissinger plots obtained for the two crystallization stages are linear, with the correlation factor $(\langle r\rangle)$ above 0.99 , indicating that kinetics of crystallization processes in these alloys are of the first order. Activation energies of different crystallization processes along with other crystallization parameters viz. onset, peak temperature and enthalpy, are given in table 1 . The variation of activation energy values of first and second crystallization peaks with silicon content is plotted in figure 5. It is observed that the alloy with $1 \%$ silicon shows minimum activation energy value for the first crystallization. It is also observed that the activation energy values increased with the silicon con-

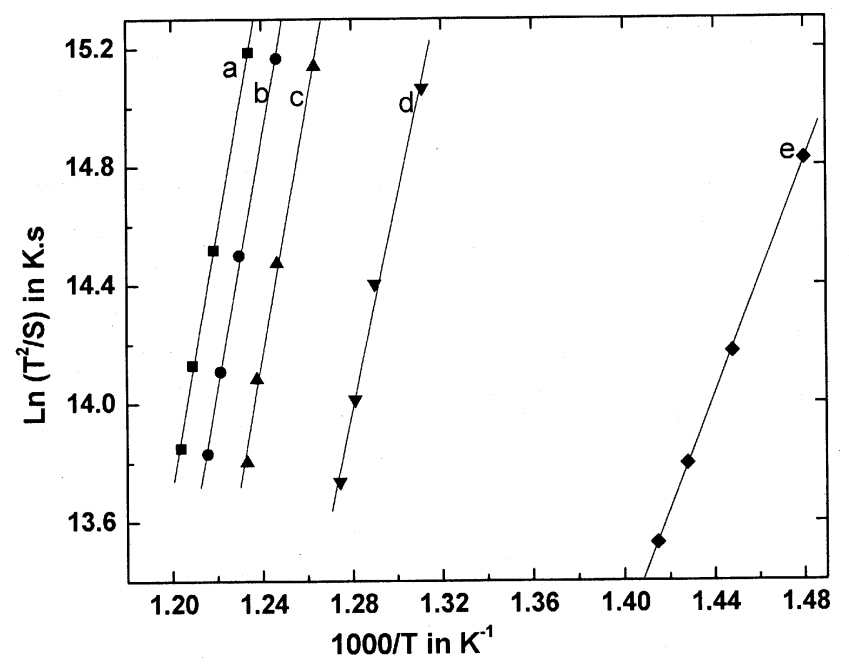

Figure 3. Kissinger plots of the 1st crystallization process of the melt spun ribbons with different $\mathrm{Si}$ contents: $\mathrm{a}$. $\mathrm{Si}=15 \%$, b. $\mathrm{Si}=12 \cdot 2 \%$, c. $\mathrm{Si}=9 \cdot 4 \%$, d. $\mathrm{Si}=6.6 \%$ and $\mathrm{e} . \mathrm{Si}=1 \%$. tent. However, the activation energy values remained more or less the same for silicon content above $9 \%$. The alloy with $1 \%$ silicon also shows the minimum activation energy value for the second crystallization step. It is well known that the changes in magnetic properties of the materials during high temperature applications are mainly due to the primary crystallization process. Therefore, the time constants for the transformation processes associated with the primary crystallization of these alloys were also determined by Kissinger (1956) analysis and shown in figure 6. The correlation factor $(\langle r\rangle)$ for all the ribbons was above 0.99 . The expressions obtained for melt-spun ribbons with different silicon contents are given below:

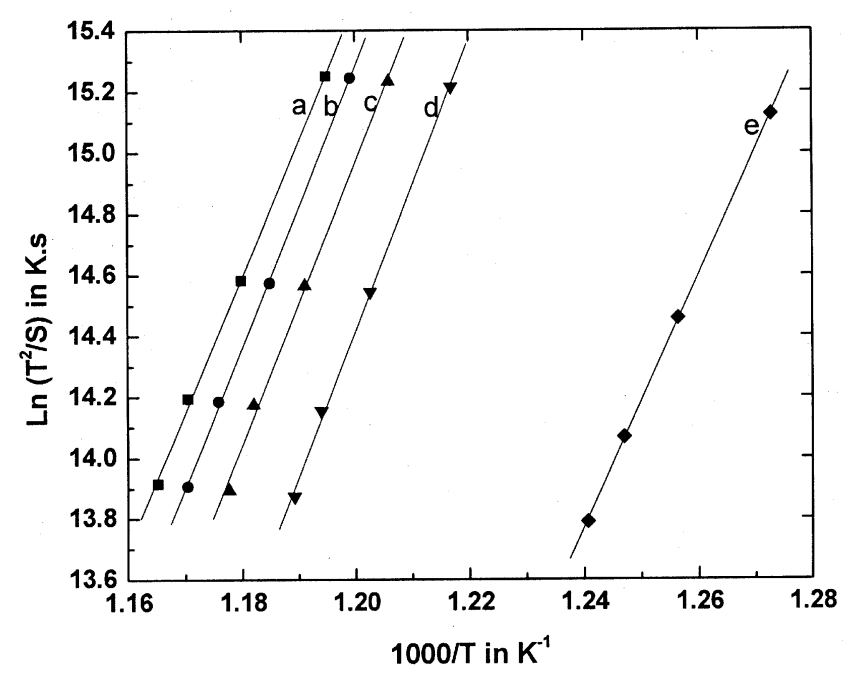

Figure 4. Kissinger plots of the 2nd crystallization process of the melt spun ribbons with different $\mathrm{Si}$ contents: $\mathrm{a} . \mathrm{Si}=15 \%$, b. $\mathrm{Si}=12.2 \%$, c. $\mathrm{Si}=9.4 \%, \mathrm{~d} . \mathrm{Si}=6.6 \%$ and $\mathrm{e} . \mathrm{Si}=1 \%$.

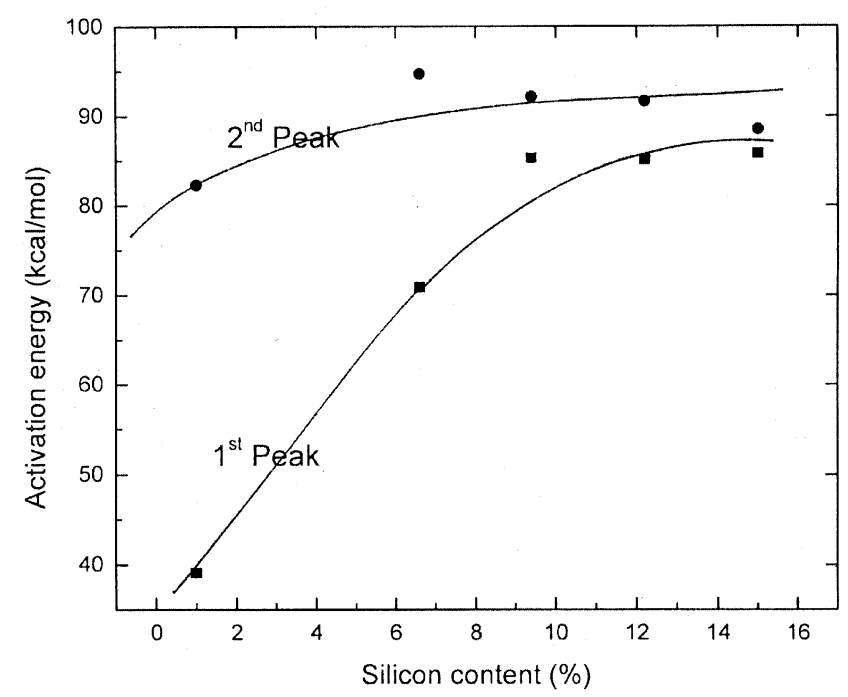

Figure 5. The variation of the activation energy values of first and second crystallization peaks with the silicon content. 
Table 1. Crystallization parameters of $\left(\mathrm{Fe}_{0 \cdot 79} \mathrm{Co}_{0 \cdot 21}\right)_{75+x} \mathrm{Si}_{15-1 \cdot 4 x} \mathrm{~B}_{10+0 \cdot 4 x}$ alloys with different $\mathrm{Si}$ contents.

\begin{tabular}{|c|c|c|c|c|c|c|c|c|}
\hline \multirow[b]{2}{*}{ Sample } & \multicolumn{4}{|c|}{ First crystallization } & \multicolumn{4}{|c|}{ Second crystallization } \\
\hline & $T_{\text {onset } 1}(\mathrm{~K})$ & $T_{\mathrm{p} 1}(\mathrm{~K})$ & $\Delta H_{1}(\mathrm{~J} / \mathrm{g})$ & $E_{1}(\mathrm{kcal} / \mathrm{mol})$ & $T_{\text {onset2 }}(\mathrm{K})$ & $T_{\mathrm{p} 2}(\mathrm{~K})$ & $\Delta H_{2}(\mathrm{~J} / \mathrm{g})$ & $E_{2}(\mathrm{kcal} / \mathrm{mol})$ \\
\hline $\mathrm{Si}=15$ & $799 \cdot 6$ & $810 \cdot 2$ & $32 \cdot 98$ & $85 \cdot 73$ & $828 \cdot 6$ & $836 \cdot 9$ & $72 \cdot 1$ & $88 \cdot 48$ \\
\hline $\mathrm{Si}=12 \cdot 2$ & $790 \cdot 1$ & $802 \cdot 2$ & $36 \cdot 7$ & $85 \cdot 07$ & $826 \cdot 4$ & 833.9 & $70 \cdot 9$ & $91 \cdot 62$ \\
\hline $\mathrm{Si}=9.4$ & 776.9 & $791 \cdot 5$ & $81 \cdot 81$ & $85 \cdot 28$ & 822.9 & $829 \cdot 2$ & $55 \cdot 6$ & $92 \cdot 15$ \\
\hline $\mathrm{Si}=6 \cdot 6$ & $747 \cdot 7$ & $762 \cdot 5$ & $92 \cdot 41$ & $70 \cdot 91$ & $815 \cdot 5$ & $821 \cdot 7$ & $91 \cdot 7$ & $94 \cdot 69$ \\
\hline $\mathrm{Si}=1$ & $658 \cdot 4$ & $675 \cdot 6$ & $96 \cdot 04$ & $39 \cdot 08$ & $779 \cdot 8$ & $785 \cdot 7$ & $91 \cdot 6$ & $82 \cdot 28$ \\
\hline
\end{tabular}

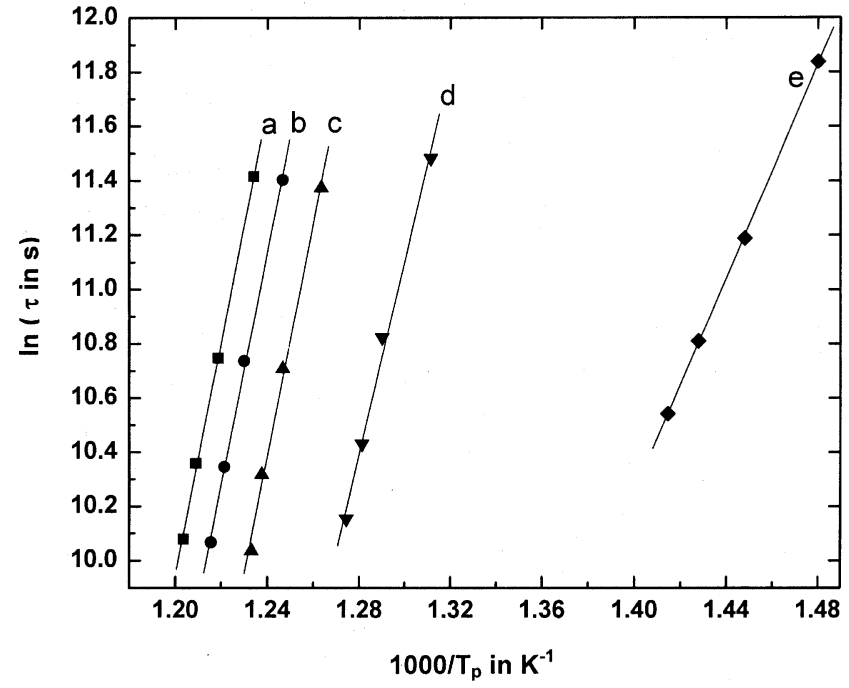

Figure 6. Time constants for the primary crystallization of the melt spun ribbons with different $\mathrm{Si}$ contents: a. $\mathrm{Si}=15 \%$, b. $\mathrm{Si}=12 \cdot 2 \%$, c. $\mathrm{Si}=9 \cdot 4 \%$, d. $\mathrm{Si}=6.6 \%$ and $\mathrm{e} . \mathrm{Si}=1 \%$.

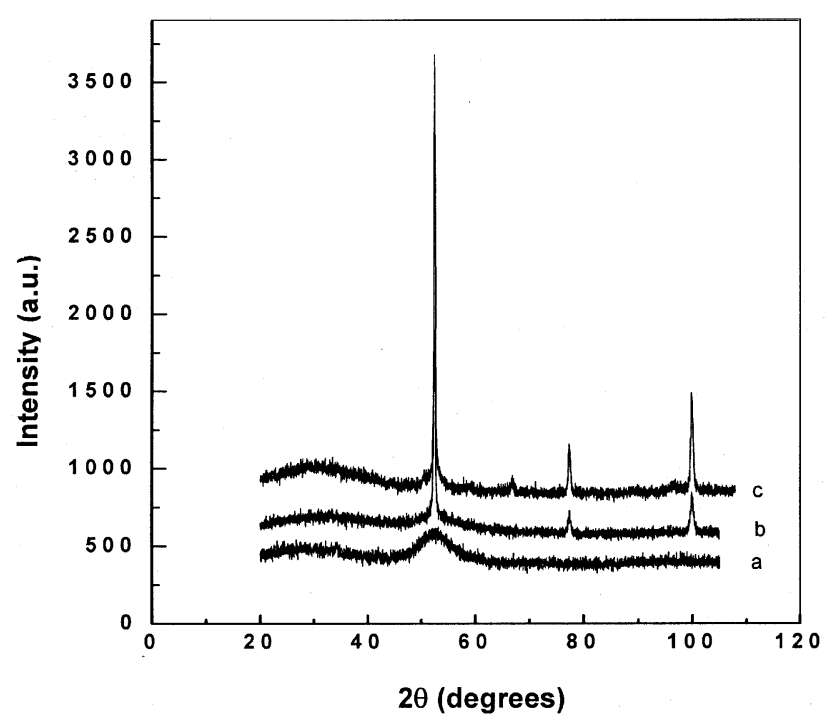

Figure 7. The X-ray diffraction pattern of the as-received and annealed samples: a. as-received, b. annealed after the first exothermic peak and c. annealed after the second exothermic peak. for $15 \% \mathrm{Si}$,

$$
\ln \tau=43 \cdot 145 \times 10^{3} / T-48 \cdot 738,
$$

for $12.2 \% \mathrm{Si}$,

$$
\ln \tau=42 \cdot 813 \times 10^{3} / T-48 \cdot 859,
$$

for $9.4 \% \mathrm{Si}$,

$$
\ln \tau=42.919 \times 10^{3} / T-47.439,
$$

for $6.6 \% \mathrm{Si}$,

$$
\ln \tau=35 \cdot 691 \times 10^{3} / T-42 \cdot 202,
$$

and for $1 \% \mathrm{Si}$,

$$
\ln \tau=19 \cdot 668 \times 10^{3} / T-24 \cdot 188 .
$$

Using the above equations from (6)-(10), stability of the amorphous phase at a given temperature, could be determined.

\subsection{X-ray diffraction}

Structural characterization of amorphous to crystalline transformation of these alloys was done by X-ray diffraction. Figure 7 shows the X-ray diffraction pattern of as-cast and heat-treated samples. X-ray diffraction pattern of the as-quenched samples indicated a broad hump with intensity maximum at diffraction angles, $2 \theta$, at around $52^{\circ}$ $\left(\mathrm{CoK}_{\alpha}\right)$ (figure 7a). X-ray diffraction pattern of the samples annealed just after the first exothermic peak (figure $7 \mathrm{~b}$ ) revealed the presence of $\mathrm{Fe}_{3} \mathrm{Si}$ and $\mathrm{Co}_{3} \mathrm{Fe}_{7}$. Samples annealed after the second exothermic peak (figure 7c) indicated the peaks of $\mathrm{Fe}_{3} \mathrm{~B}$ in addition to the peaks of $\mathrm{Fe}_{3} \mathrm{Si}$ and $\mathrm{Co}_{3} \mathrm{Fe}_{7}$. X-ray diffraction pattern of these samples also show a broad peak, which can be attributed to the remaining amorphous phase (Mathur et al 1987; Nagarajan et al 1988; Trudeau et al 1990; Stergioudis et al 1992; Conde et al 1993).

\subsection{Magnetic measurements}

The coercivity $\left(H_{\mathrm{c}}\right)$ of the metallic ribbons was measured in as received and annealed samples. The results are tabulated 
Table 2. Coercivity of as received and annealed ribbons of $\left(\mathrm{Fe}_{0.79} \mathrm{Co}_{0.21}\right)_{75+x} \mathrm{Si}_{15-1 \cdot 4 x} \mathrm{~B}_{10+0.4 x}$ alloys with different $\mathrm{Si}$ contents.

\begin{tabular}{lcc}
\hline & \multicolumn{2}{c}{ Coercivity $\left(H_{\mathrm{c}}\right)(\mathrm{A} / \mathrm{m})$} \\
\cline { 2 - 3 } Sample & As received & Annealed at $523 \mathrm{~K}$ \\
\hline $\mathrm{Si}=15$ & $3 \cdot 57$ & $6 \cdot 62$ \\
$\mathrm{Si}=12 \cdot 2$ & $4 \cdot 47$ & 3.91 \\
$\mathrm{Si}=6 \cdot 6$ & $10 \cdot 52$ & $18 \cdot 08$ \\
$\mathrm{Si}=1$ & $3 \cdot 13$ & $28 \cdot 29$ \\
\hline
\end{tabular}

in table 2. It is observed that the coercivity of the as received samples were low $(<4.47 \mathrm{~A} / \mathrm{m})$ except for one sample $(\mathrm{Si}=6 \cdot 6 \%)$. Moreover, coercivity showed a decreasing trend with increasing $\mathrm{Si}$ content barring the ribbons having $1 \%$ silicon. In most of the cases, coercivity values increased with annealing indicating the deterioration of the soft magnetic properties. However, the coercivity of ribbons with $12 \cdot 2 \%$ silicon decreased after annealing. As described earlier, the crystallization temperature increased with increasing silicon content and got saturated at higher Si\%. Similar behaviour was observed in the activation energy values too. As the coercivity of the alloy ribbon with $12.2 \%$ silicon decreased after annealing, it became magnetically superior. Therefore, it appears that the optimum magnetic properties could be obtained for the alloys with Si-content close to $12 \%$.

\section{Conclusions}

The thermal stability of the FeCoSiB alloy ribbons were found to decrease with increasing Si content as indicated by the drop in the crystallization onset temperature. The continuous heating experiments on DSC indicated twotemperature resolved exotherms partially overlapping at higher silicon content. X-ray diffraction revealed the formation of $\mathrm{Fe}_{3} \mathrm{Si}$ and $\mathrm{Co}_{3} \mathrm{Fe}_{7}$ phases corresponding to the first exothermic peak. The second peak corresponds to the phases of $\mathrm{Fe}_{3} \mathrm{~B}$ in addition to $\mathrm{Fe}_{3} \mathrm{Si}$ and $\mathrm{Co}_{3} \mathrm{Fe}_{7}$ phases. The coercivity of most of the ribbons increased with annealing indicating the deterioration of soft magnetic property. However, the coercivity of the ribbon with $12.2 \%$ silicon content decreased after annealing indicating better magnetic properties. The present experimental results indicated that the materials having silicon around $12.2 \%$ exhibited high crystallization temperature, better thermal stability and good soft magnetic properties. Thus, material with nominal composition, $\left(\mathrm{Fe}_{0.79} \mathrm{Co}_{0.21}\right)_{77} \mathrm{Si}_{12 \cdot 2} \mathrm{~B}_{10 \cdot 8}$, could be used for further study.

\section{References}

Conde C F, Millan M and Conde C 1993 Key Eng. Mater. 8183311

Kavesh S 1976 Materials science seminar (New York: American Society for Metals)

Kissinger H E 1956 J. Res. NBS 57217

Libermann H H 1983 Amorphous metallic alloys (ed.) F E Luborsky (London: Butterworths) p. 26

Masumoto T and Egami T 1981 Mater. Sci. Eng. 48147

Mathur R P, Murthy V N, Akthar D, Subramanian P and Jagannathan R 1987 J. Mater. Sci. 61019

Mitra A, Kim H Y, Shen B, Nishiyama N and Inoue A 2003 Mater. Trans. 441562

Mittemeijer E J, Chang L, van der Schaaf P J, Brakman C M and Korevaar B M 1988 Metall. Trans. A19 925

Nagarajan T, Chidambaram Assari U, Srinivasan S, Sridharan V and Narayanasamy A 1988 Mater. Sci. Eng. 97355

Panda A K, Roy S, Singh S R, Rao V, Pramanick S, Chattoraj I, Mitra A and Ramachandrarao P 2001 Mater. Sci. Engg. A304 457

Stergioudis G A, Ynkinthos J, Rentzeperis P J, Bojarski Z and Panek T J 1992 J. Mater. Sci. 272468

Trudeau M I, Huot J-Y and Scjhulz R 1990 J. Appl. Phys. 67 2333 